\title{
A Demand-Side Perspective on Developing a Future Electricity Generation Mix: Identifying Heterogeneity in Social Preferences
}

\author{
Sung-Yoon Huh ${ }^{1}$ and Chul-Yong Lee ${ }^{2, *}$ \\ 1 Haas School of Business, University of California Berkeley, 2220 Piedmont Avenue, \\ Berkeley, CA 94720, USA; sunghuh@berkeley.edu \\ 2 Korea Energy Economics Institute (KEEI), 405-11 Jongga-ro, Jung-gu, Ulsan 44543, Korea \\ * Correspondence: cylee@keei.re.kr; Tel.: +82-52-714-2289
}

Received: 17 May 2017; Accepted: 26 July 2017; Published: 1 August 2017

\begin{abstract}
Public support is an important factor in failure or success of the government decisions with respect to the electricity generation mix, which highlights the necessity of developing an electricity mix that reflects social preferences and acceptance. This study explores heterogeneity in social preferences for power sources and develops an electricity mix from a demand-side perspective. The study utilizes the choice-based conjoint survey and latent class model, and bases its empirical analysis on South Korea's electric power sector. Results demonstrate that preferences for power sources in Korean society consist of two classes: one that is sensitive to the environment and one that is sensitive to risk. An electricity mix for Korea that reflects social preferences is 16.5-19.8\% coal-fired, 13.3-24.9\% liquefied natural gas (LNG), 9.0-11.2\% oil, 22.3-32.9\% nuclear, and 18.5-38.9\% renewables, depending on the scenario. The study confirms that renewables are the power source with the least potential to cause social conflict, compared to nuclear and coal-fired sources. Moreover, increasing the proportion of renewables (currently only 3.9\%) while decreasing the proportion of coal-fired power sources (currently 39.9\%) to less than half its current level will result in an electricity mix that is accordance with social preferences in the long run.
\end{abstract}

Keywords: electricity mix; public acceptance; stated preference method; discrete choice model; latent class model; South Korea

\section{Introduction}

The national energy mix is important as a strategic plan to fulfill the objectives of energy policies. The electricity mix, which is the core of the energy mix, is the basis for the national electric-power policy and directly affects the expansion of electric-power facilities and the investment plan. Hence, it is important to the future electric-power supply. In addition, the established electricity mix influences policies for primary energy sources, such as oil and gas, and has become a major issue in energy policies. Most countries try to build a stable electric-power supply system by planning the optimal electricity mix and designing corresponding policies.

To provide a stable electric-power supply, a country generally needs an electricity mix comprising various fuel sources. This is especially true for countries like South Korea, which is highly dependent on energy imports (as of 2016, South Korea's dependence on energy imports was about 95\% [1]). However, the traditionally-planned optimal electricity mix has focused on reducing the "nominal" cost of electric-power production. That is, it has focused only on least-cost stand-alone $\mathrm{kWh}$ generating cost measures without considering other related risks of electricity generation [2]. This will inherently result in a high ratio of fossil fuels [3]. However, a paradigm shift of energy policy has taken place recently, as the importance of "external" costs of electricity generation has been emphasized. All power generation 
technologies are accompanied by these externalities, costs imposed on individuals or the community that are not paid for by the producer or consumer of electricity [4]. Examples of such external costs include human health problems, environmental degradation, energy security, dangers of a major accident with a power plant, etc. In recent years, recognition and responsibility for such external costs of electricity and their internalization have become an important policy issue [5], and thus, recent studies have proposed an electricity mix developed under various constraints [2,3,6-18]. This context might explain the global phenomenon in which the proportion of renewable energy is increasing even though it has a lower economic feasibility than conventional energy sources. To prepare for a long-term, sustainable electric-power system, it has become essential to not only focus on minimizing stand-alone $\mathrm{kWh}$ generating costs when developing the electricity mix.

Social acceptance is one factor that must be considered to establish an electricity mix that reflects the change in the external environment, because the shift to a sustainable electricity mix, and away from fossil fuels could cause an increase in the cost of electric-power production. Whether customers will accept an increase in the cost of electric-power production when it is ultimately passed to them as electricity charges-and what level of increase the customers will accept-is an important issue when preparing for an electricity mix that accounts for external costs. The social acceptance of such electricity generation sources will become important in the future, and must be considered as the key element when determining the electricity mix $[19,20]$.

Another factor that must be considered when developing the future electricity mix is the heterogeneity of social preferences for power sources. Each individual power source, such as coal-fired, nuclear, or renewable sources, has its own advantages and disadvantages, thus each consumer might have a different opinion on the power source. The development of an electricity mix that accounts for only the average preference and not the heterogeneity of social preferences may exacerbate social conflicts. Hence, a policy that reflects the details of heterogeneity of preferences for power sources must be enforced. Recent studies have addressed the heterogeneity of preferences for power source and energy technology [21-24].

This study develops an electricity mix that maximizes consumers' utility from a demand-side perspective. It estimates preferences for power sources considering the heterogeneity of electric-power consumers. Additionally, scenario analysis is conducted to understand consumer preferences that are influenced by the change in power source attributes, such as the levelized cost of electricity (LCOE). To achieve the objectives of this study, a choice-based conjoint (CBC) survey to collect stated preferences (SP) data for power sources and the latent class model (LCM) is conducted, and a discrete choice model (DCM) is also utilized. Through the proposed methodology, the study conducts an empirical analysis of South Korea's power sector. The electricity mix developed from a demand-side perspective in this study provides meaningful implications for developing a future national electricity mix, together with the previous studies from supply-side perspectives.

This paper is organized as follows. Section 2 conducts a literature review of relevant studies. Section 3 proposes a method to apply LCM to deduct the electricity mix from a demand-side perspective. Section 4 describes the structure of a CBC survey to collect SP data. Section 5, which illustrates the results of the empirical analysis, proposes the estimation results and future electricity mix from a demand-side perspective. Finally, Section 5 suggests limitations and future research directions.

\section{Literature Review: Optimal Electricity Generation Mix}

Studies that derive the optimal electricity mix often utilize an optimization technique, and the traditional approach minimizes the objective function of power generation cost. Most programs such as WASP IV, EMCAS, UPLAN, and AURORAxmp use such functions [25,26]. On the other hand, recent studies have considered not only such nominal costs of power generation but also the external costs or policy objectives—such as environmental effects [6-9], energy security [2,10,11], related risk [3,12-14], future uncertainty [15], and other energy policy goals [16-18] —as additional constraints. Most of 
these studies utilize a multi-objective optimization model or portfolio theory. Hence, studies on the development of an electricity mix have mainly been conducted from a supply-side perspective.

A few studies examined the electricity mix from the perspective of consumer preferences. Grösche and Schröder [27] examined whether respondents are supportive of various electricity mixes by analyzing survey data. Some studies investigate public opinion on the electricity mix in an analysis of consumer preferences for electric-power services [28,29]. These studies directly address the electricity mix to respondents by including the proportion of power source in the choice experiment attributes. However, because the quality of electricity by type of power source produced does not change much for end-customers, customers express their preferences for attributes that occur with electric-power supply rather than expressing preferences for the power source itself. Hence, there is a limit to the direct analysis of consumer preferences based on the suggestion of power source [30]. In addition, this method cannot predict the change in electricity mix by the change in attributes of the power source, and it is difficult to effectively reflect the heterogeneity in respondents' preferences in the development of the electricity mix.

Therefore, this study differs by developing an electricity mix that maximizes consumer utility using power source attributes. Additionally, the study classifies consumer classes with a similar preference structure reflecting the consumers' heterogeneity and analyzes the change of preferences for power source by class. Moreover, by comparison with existing studies, it is possible to predict whether the long-term electricity mix developed from a supply-side perspective can be socially accepted or not.

\section{Materials and Methods}

\subsection{The Model}

This study utilizes DCM to derive the electricity mix from a demand-side perspective. Based on a random utility model, DCM assumes that $U_{i j t}$, the utility that respondent $i$ obtains from the $j^{\text {th }}$ alternative within the $t^{\text {th }}$ choice set, consists of deterministic utility $\left(V_{i j t}\right)$, which respondents can observe, and random disturbance $\left(\varepsilon_{i j t}\right)$, which respondents cannot observe. $V_{i j t}$ consists of the linear combination of $K$ independent variables $\left(X_{j k t}\right)$ and $K$ parameters $\left(\beta_{k}\right)$ (Equation (1)).

$$
U_{i j t}=V_{i j t}+\varepsilon_{i j t}=\sum_{k=1}^{K} \beta_{k} X_{j k t}+\varepsilon_{i j t}
$$

DCM assumes the utility maximization of respondents who choose the alternative that gives the highest utility. When $Y_{i t}$ is the choice variable, which represents the alternative that a respondent $i$ prefers among $J$ alternatives within the $t^{\text {th }}$ choice set, the choice of a respondent who chooses the $j^{\text {th }}$ electric-power supply alternative can be illustrated as in Equation (2):

$$
Y_{i t}=j \text { if } U_{i j t} \geq U_{i h t}, \forall h \neq j
$$

In Equation (1), if $\varepsilon_{i j t}$ is assumed to be an independent and identically distributed (i.i.d.) type I extreme value for all alternatives, the model becomes the multinomial logit (MNL) model, one of the most common models among DCM. Assuming the MNL model, the probability that a respondent $i$ chooses an alternative $j$ within the $t^{\text {th }}$ alternative set is given by Equation (3) [31]. Here, $I(\cdot)$ is the indicator function that has a value of one if the value in parentheses is true or zero if it is false.

$$
\begin{aligned}
P_{i j t} & =\operatorname{Pr}\left(Y_{i t}=j\right)=\operatorname{Pr}\left(U_{i j t} \geq U_{i h t}, \forall h \neq j\right) \\
& =\int_{\varepsilon} I\left(V_{i j t}+\varepsilon_{i j t} \geq V_{i h t}+\varepsilon_{i h t}, \forall h \neq j\right) f\left(\varepsilon_{i j t}\right) d \varepsilon_{i j t} \\
& =\frac{\exp \left(V_{i j t}\right)}{\sum_{h=1}^{J} \exp \left(V_{i h t}\right)}=\frac{\exp \left(\sum_{k=1}^{K} \beta_{k} X_{j k t}\right)}{\sum_{h=1}^{J} \exp \left(\sum_{k=1}^{K} \beta_{k} X_{h k t}\right)}
\end{aligned}
$$


The MNL model has the limitation that it does not reflect the preference heterogeneity because it assumes that all respondents have an identical preference structure [31]. To overcome this limitation, this study utilizes LCM to analyze social preferences for power sources.

LCM is widely used in the fields of marketing and psychology [31,32]. LCM assumes that consumers can be classified into $Q$ potential classes based on their preferences. It assumes that consumers in each class have identical preference structures, and that the coefficient of the utility function for each class consumer is equal $[31,33]$. Since the probability of membership, which represents the probability that a consumer will belong to each class, can be calculated, it is possible to segment consumers based on class. As such, LCM has a strong theoretic basis because it segments consumers based on the economic model of consumer preferences [34]. The utilization of LCM can not only ensure that consumers have heterogeneous preferences but also segment them based on their preferences.

In LCM, the utility that a consumer $i$ in the $q^{\text {th }}$ class obtains from the $j^{\text {th }}$ electric-power supply alternative in the $t^{\text {th }}$ alternative set is given by Equation (4):

$$
U_{i j \mid q}=\sum_{k=1}^{K} \beta_{q k} X_{j k t}+\varepsilon_{i j t}
$$

When it is assumed that $\varepsilon_{i j t}$ follows the type I extreme value distribution, the probability that a consumer $i$ who belongs to the $q^{\text {th }}$ class chooses the $j^{\text {th }}$ electric-power supply alternative within the $t^{\text {th }}$ alternative set is given as:

$$
\begin{aligned}
P_{i j t \mid q} & =\operatorname{Pr}\left(Y_{i t}=j \mid \text { class }=q\right) \\
& =\operatorname{Pr}\left(U_{i j t \mid q} \geq U_{i h t \mid q,}, \forall h \neq j \mid \text { class }=q\right) \\
& =\frac{\exp \left(\sum_{k=1}^{K} \beta_{k q} X_{j k t}\right)}{\sum_{h=1}^{J} \exp \left(\sum_{k=1}^{K} \beta_{k q} X_{h k t}\right)}
\end{aligned}
$$

Likewise, when it is assumed that the choices of consumers in each alternative set are independent [31], the joint probability of consumers' choices under the assumption that a consumer $i$ belongs to a class $q$ is given as:

$$
P_{i \mid q}=\prod_{t=1} \prod_{j=1} P_{i j t \mid q}
$$

It is possible to calculate the probability of membership of consumers in each class to determine the class to which a consumer would belong. Assuming that the set of observable variables that affect the probability of consumer $i$ 's membership is $z_{i}$ and that unobservable variables follow the i.i.d. type I extreme value distribution for all classes, the prior probability that a consumer $i$ belongs to class $q$ $(q=1, \ldots, Q)$ can be expressed as:

$$
H_{i q}=\frac{\exp \left(z_{i}^{\prime} \theta q\right)}{\sum_{q=1}^{Q} \exp \left(z_{i}^{\prime} \theta q\right)}
$$

To distinguish the coefficients, the value of $\theta_{Q}$, which is the coefficient of the last class $\left(Q^{\text {th }}\right)$ in the Equation (7), is fixed to zero. In other words, when interpreting the values of each coefficient derived from the result of estimation, it is necessary to explain based on the difference between each class and the last class, based on the last class. It is then possible to derive consumer $i$ 's likelihood function, which can be derived as the expected value of each class for joint probability of choice as in the above Equation (6).

$$
P_{i}=\sum_{q=1}^{Q} H_{i q} P_{i \mid q}
$$


Hence, the log-likelihood function of all $n$ respondents can be derived as the below Equation (9).

$$
\ln L=\sum_{i=1}^{n} \ln P_{i}=\sum_{i=1}^{n} \ln \left[\sum_{q=1}^{Q} H_{i q}\left(\prod_{t=1} \prod_{j=1} P_{i j t \mid q}\right)\right]
$$

Based on the above log-likelihood function, the utility function's coefficients $\left(\beta_{k q}\right)$ and coefficients in the membership probability equation $\left(\theta_{q}\right)$ can be estimated simultaneously using the maximum likelihood method. It is also possible to estimate the probability of class membership of an individual respondent and the utility function's coefficients using the Bayes theory. Under the Bayes theory, the posterior probability of consumer i's class membership is given by Equation (10).

$$
\hat{H_{q / i}}=\frac{\hat{H_{i / q}} \hat{H}_{i q}}{\sum_{q=1}^{Q} \hat{P_{i \mid q}} \hat{H}_{i q}}
$$

In addition, the coefficient of the utility function at the individual respondent's level can be derived from Equation (11) [33].

$$
\hat{\beta}_{i}=\sum_{q=1}^{Q} \hat{H_{q \mid i}} \hat{\beta_{q}}
$$

Using the results of the analysis of LCM, the marginal willingness to pay (MWTP) for each attribute can be derived for each class. Here, MWTP refers to the amount that a consumer is willing to pay to keep his/her utility the same as before when the quantity or quality of the attributes changes by one unit. The MWTP that consumers in the $q^{\text {th }}$ class have for attribute $k$ can be obtained as:

$$
\operatorname{MWTP}_{k q}=-\frac{\partial U_{i j t \mid q} / \partial X_{j k t}}{\partial U_{i j t q q} / \partial X_{\text {price }}}=-\frac{\beta_{q k}}{\beta_{q, \text { price }}}
$$

The relative importance (RI) of attributes refers to which attributes a consumer places importance on when choosing an electric-power supply alternative. The RI for an attribute $k$ of consumers in the $q^{\text {th }}$ class is calculated through the following Equation (13). The part-worth of the attributes is obtained by multiplying the difference of the maximum and minimum level of each attribute by the value of the corresponding attribute's coefficient.

$$
\mathrm{RI}_{k q}=\frac{\text { Part-worth }_{k q}}{\sum_{j=1}^{K} \text { Part-worth }_{j q}} \times 100
$$

\subsection{Data}

To derive the electricity mix that reflects social preferences, it is necessary to analyze which of the electric-power supply alternatives a consumer chooses. This study utilizes the CBC analysis to collect SP data of consumer preferences for power source. By analyzing the data through DCM, this study derives social preferences for each attribute of electric-power supply and develops an electricity mix from the demand-side perspective.

It is important to select the appropriate attributes of electric-power supply and their level. This study sets up six attributes of power sources based on a review of existing studies $[28,29,35-38]$ and experts' advices (Table 1). For other potential attributes that affect preferences for power sources, the study assumes that all alternatives have an identical level and ensures that respondents are fully aware of this during the survey. 
Table 1. Choice-based conjoint (CBC) survey attributes and their levels. KRW: Korean Won.

\begin{tabular}{|c|c|}
\hline Attributes & Level \\
\hline Greenhouse gas emissions & $\begin{array}{l}\text { No greenhouse gas emissions ( } 100 \% \text { reduction) } \\
\text { Greenhouse gas emissions at half the level of fossil fuel ( } 50 \% \text { reduction) } \\
\text { Greenhouse gas emissions at the level of fossil fuel ( } 0 \% \text { reduction) }\end{array}$ \\
\hline $\begin{array}{l}\text { Fine particulate matter emissions } \\
\text { (Air pollutant emission) }\end{array}$ & $\begin{array}{l}\text { No occurrence of fine particulate matter ( } 100 \% \text { reduction) } \\
\text { Occurrence of fine particulate matter at half the current level ( } 50 \% \text { reduction) } \\
\text { Occurrence of fine particulate matter at the current level ( } 0 \% \text { reduction) }\end{array}$ \\
\hline Electricity charges & $\begin{array}{l}\text { Half of current electricity charges }(50 \% \text { decrease, } 63 \mathrm{KRW} / \mathrm{kWh}) \\
\text { Current level of electricity charges }(0 \% \text { increase, } 125 \mathrm{KRW} / \mathrm{kWh}) \\
\text { Twice the current electricity charges }(100 \% \text { increase, } 250 \mathrm{KRW} / \mathrm{kWh})\end{array}$ \\
\hline Risk & $\begin{array}{l}\text { High: possible local damage such as radiation poisoning } \\
\text { Low: almost no damage from earthquake or war }\end{array}$ \\
\hline $\begin{array}{l}\text { Annual outage time } \\
\text { (electric-power supply stability) }\end{array}$ & $\begin{array}{l}\text { About } 0 \mathrm{~min} / \text { year (almost no outage per household in a year) } \\
\text { About } 30 \mathrm{~min} / \text { year (about } 30 \text {-min outage per house in a year) }\end{array}$ \\
\hline $\begin{array}{l}\text { Dependence on the import of } \\
\text { energy source }\end{array}$ & $\begin{array}{l}0 \% \text { import of energy source } \\
100 \% \text { import of energy source }\end{array}$ \\
\hline
\end{tabular}

The first attribute, the greenhouse gas emission, reflects the difference in carbon emissions that cause climate change by power source. The study identifies the ratio of greenhouse gas emission reduction, compared to fossil fuel use, establishing three levels of reduction $(100 \%, 50 \%$, and $0 \%)$.

The second attribute, the amount of fine particulate matter (including $\mathrm{PM}_{10}, \mathrm{NO}_{x}$, and $\mathrm{SO}_{2}$ ), varies depending on the type of power source. In Korea, the fine particulate matter emissions due to electric-power generation have recently emerged as an important issue. The study assumes that the amount of fine particulate matter emission differs across the type of power sources and establishes three levels of reduction $(100 \%, 50 \%$, and $0 \%$ ) based on the current fine particulate matter emission amount.

The third attribute, electricity charges, is an attribute that must be included to derive a consumer's MWTP for each attribute. Because power generation cost varies depending on the type of power source, the choice of power source could affect the electricity charge if it is passed on to consumers. This study assumes that electric-power production cost is related to the electricity charges and derives the level of this attribute considering the LCOE of each power source. Hence, the level of this attribute is categorized as half the current rate $(63 \mathrm{KRW} / \mathrm{kWh}$; KRW stands for Korean Won, and as of 1 June 2016, USD $1=\mathrm{KRW} 1192)$, current rate $(125 \mathrm{KRW} / \mathrm{kWh})$, or twice the current rate $(250 \mathrm{KRW} / \mathrm{kWh}$ ). However, a preliminary survey revealed that respondents face difficulty recognizing changes in electricity charges in units of LCOE (KRW/ kWh). Hence, the preliminary questionnaire asks for the average monthly electricity charges of respondents' households, and the electricity charges are designed to be automatically $\times 1 / 2, \times 1$, and $\times 2$ in the CBC survey. Thus, the study allows respondents to experience the actual changes in electricity charges.

The fourth attribute, risk, reflects the considerable difference in social awareness of nuclear power generation after the Fukushima disaster of 2011. The specific explanation of the risk is that "disasters, such as the Fukushima explosion, can occur when wars or natural disasters like an earthquake occur." The level of this attribute is set as "high" or "low".

The fifth attribute is outage time. While outage time is mostly related to the electric-distribution system, it can also be affected by the type of power source. The annual outage time per household in Korea is currently about four min. However, assuming that the stability of the electric-power supply could be reduced when renewable power generation expands, this study selects the levels of outage time per household to be zero min or $30 \mathrm{~min}$.

The last attribute, the dependence on the import of energy source, is related to national energy security. In Korea, most of the energy is imported, except for renewable energy. The level of this attribute is established as $100 \%$ import of energy source or $0 \%$ import of energy source. 
The number of alternatives that can be obtained through the combination of attributes and levels shown in Table 1 is 216 . However, it is not appropriate to present all alternatives due to reasons including respondents' bounded rationality, time, and cost constraints. Hence, this study selects 16 alternatives after applying the orthogonal plan among factional factorial designs. The aim of the orthogonal plan is to have the smallest manageable combination of potential alternatives to test with respondents. The orthogonal plan seeks a balanced design in which each level in each attribute appears the same number of times. These 16 alternatives were randomly mixed and then classified into four sets, each of which consists of four alternatives (see Appendix A). Respondents are asked to select the alternative that they prefer the most among the four alternatives within the selected set.

The actual fieldwork was conducted by a professional research company (Korea Research) through an online web survey based on structured questionnaires. The survey data were collected from 615 Korean adults aged 19 years or older from June 17 to 26 in 2016. Since this study is related to the usage of household electric-power, it limits the survey participants to household heads and their partners to improve the reliability of data. Survey respondents were selected via purposive-quota sampling to make sample data similar to the actual population composition of Korea. Table 2 summarizes key characteristics of the respondents.

Table 2. Key characteristics of the respondents.

\begin{tabular}{|c|c|c|c|}
\hline \multicolumn{2}{|c|}{ Characteristics } & Number of Respondents & Component Ratio (\%) \\
\hline \multicolumn{2}{|c|}{ Total } & 615 & 100 \\
\hline \multirow{2}{*}{ Gender } & Male & 311 & 50.6 \\
\hline & Female & 304 & 49.4 \\
\hline \multirow{5}{*}{ Age } & $19-29$ & 108 & 17.6 \\
\hline & $30-39$ & 112 & 18.2 \\
\hline & $40-49$ & 130 & 21.1 \\
\hline & $50-59$ & 126 & 20.5 \\
\hline & $>60$ & 139 & 22.6 \\
\hline \multirow{4}{*}{ Education Level } & Under High school & 197 & 32.0 \\
\hline & College & 36 & 5.9 \\
\hline & University & 19 & 3.1 \\
\hline & Above graduate school & 363 & 59.0 \\
\hline \multicolumn{2}{|c|}{ Average Monthly Income (USD) } & & \\
\hline
\end{tabular}

\section{Results and Discussion}

\subsection{Heterogeneity in Social Preferences for Electricity Attributes}

This section presents the analysis result of consumer preferences for electricity attributes as the preliminary work for developing an electricity mix from a demand-side perspective. This study assumes that there are multiple respondent classes for power source preference and utilizes LCM to reflect the heterogeneity in social preferences.

The number of classes is entered by the researcher when performing LCM analysis. We can see the most obvious utility difference for power source preference between classes when entering two classes. The relative importance (IR) of Tables 3 and 4 shows that class 1 is relatively sensitive to the environmental attribute among power source attributes and consists of 313 respondents $(50.9 \%$ of all respondents), and class 2 is relatively sensitive to the risk attribute and consists of 302 respondents (49.1\% of all respondents). The reason that the two classes are identified as classes relatively sensitive to a power source's environment and risk attributes, respectively, can be understood by analyzing the result of class preferences (Tables 3 and 4). 
Table 3. Latent class model (LCM) estimation result (1): class 1's preference for power source. MWTP: marginal willingness to pay; RI: relative importance.

\begin{tabular}{|c|c|c|c|c|}
\hline Attribute & Estimates & Standard Deviation & MWTP & RI \\
\hline $\begin{array}{c}\text { Greenhouse gas emission } \\
\text { reduction }(1 \%)\end{array}$ & $0.0146^{* * *}$ & 0.0029 & $1.37 \mathrm{KRW} / \mathrm{kWh} \% \%$ & $21.5 \%$ \\
\hline $\begin{array}{l}\text { Fine particulate matter } \\
\text { emission reduction }(1 \%)\end{array}$ & $0.0144^{* * *}$ & 0.0029 & $1.35 \mathrm{KRW} / \mathrm{kWh} \% \%$ & $21.2 \%$ \\
\hline $\begin{array}{c}\text { Electricity charges } \\
\text { (KRW/kWh) }\end{array}$ & $-0.0107^{* * *}$ & 0.0024 & - & $29.3 \%$ \\
\hline Risk $($ High $=1)$ & $-0.5763^{* * *}$ & 0.2179 & $-54.08 \mathrm{KRW} / \mathrm{kWh}$ & $8.5 \%$ \\
\hline Annual outage (1 min) & $-0.0174^{* * *}$ & 0.0037 & $-1.63 \mathrm{KRW} / \mathrm{kWh} \cdot \mathrm{min}$ & $7.7 \%$ \\
\hline $\begin{array}{c}\text { Dependence on the import } \\
\text { of energy source }(1 \%)\end{array}$ & $-0.0081^{* * *}$ & 0.0009 & $-0.76 \mathrm{KRW} / \mathrm{kWh} \%$ & $11.9 \%$ \\
\hline
\end{tabular}

Table 4. LCM estimation result (2): class 2's preference for power source.

\begin{tabular}{|c|c|c|c|c|}
\hline Attribute & Estimates & Standard Deviation & MWTP & RI \\
\hline $\begin{array}{c}\text { Greenhouse gas emission } \\
\text { reduction }(1 \%)\end{array}$ & 0.0000 & 0.0013 & $0.01 \mathrm{KRW} / \mathrm{kWh} \% \%$ & $0.1 \%$ \\
\hline $\begin{array}{l}\text { Fine particulate matter } \\
\text { emission reduction }(1 \%)\end{array}$ & $-0.0053^{* * *}$ & 0.0018 & $-0.94 \mathrm{KRW} / \mathrm{kWh} \%$ & $12.7 \%$ \\
\hline $\begin{array}{c}\text { Electricity charges } \\
(\mathrm{KRW} / \mathrm{kWh})\end{array}$ & $-0.0057^{* * *}$ & 0.0009 & - & $25.1 \%$ \\
\hline Risk $($ High $=1)$ & $-1.6199 * * *$ & 0.1961 & $-286.47 \mathrm{KRW} / \mathrm{kWh}$ & $38.5 \%$ \\
\hline Annual outage (1 min) & $-0.0168^{* * *}$ & 0.0051 & $-2.97 \mathrm{KRW} / \mathrm{kWh} \cdot \min$ & $12.0 \%$ \\
\hline $\begin{array}{l}\text { Dependence on the import } \\
\text { of energy source }(1 \%)\end{array}$ & $-0.0049^{* * *}$ & 0.0008 & $-0.87 \mathrm{KRW} / \mathrm{kWh} \%$ & $11.7 \%$ \\
\hline
\end{tabular}

The estimation results of Tables 3 and 4 include all the six attributes of electric-power supply presented in Table 1. Each estimated coefficient shows how the change in the level of a power source attribute affects the utility of consumers in each class. For example, regarding electricity production, the utility of a consumer in class 1 increases by 0.0146 if greenhouse gas emissions are reduced by $1 \%$ compared with the emissions from fossil fuels; the utility of a consumer in class 1 decreases by 0.5763 if annual power outage increases by $1 \mathrm{~min}$. The other signs of estimated coefficients in Table 3 show that consumers in class 1 prefer a power source with relatively low greenhouse gas and fine particulate matter emissions, low electricity charges, low risk, low outage hours, and low dependence on the import of energy source. These results are consistent with the common perception, and electric-power producers also generally support this direction to improve the electric-power supply. On the other hand, in Table 4, the signs of parameter estimates for fine particulate matter emission reduction in class 2 differ from the general perception. Given that the RI of attributes other than risk and electricity charges attributes are low in the estimation result of class 2 , the result could have been rendered because, while respondents in class 2 generally consider risk and electricity charges attributes, they do not consider the fine particulate matter emission attribute much when choosing power sources.

The result of RI shows that respondents, regardless of class, consider the level of electricity charges an important factor (class 1: $29.3 \%$, class 2: $25.1 \%$ ). This is consistent with the results of existing studies $[28,29]$. However, for attributes other than the electricity charge attribute, there is a clear difference between the two classes. When deciding on electric-power supply, respondents in class 1 place importance on greenhouse emission reduction $(21.5 \%)$ and fine particulate matter emission reduction $(21.2 \%)$, which are very high compared to the RI of these attributes in class 2 . Considering that the two attributes are both related to the environment, class 1 can be defined as the group that is relatively sensitive to the environmental effect of power sources. On the other hand, the 
most noticeable issue in class 2 is that the risk attribute took $38.5 \%$ of RI. This is clearly different from class 1, where the RI of the risk attribute is low. Hence, class 2 can be defined as the group that is relatively sensitive to the risk of power sources.

In regards to the MWTP for each attribute, as expected, consumers in class 1 were willing to pay a much higher amount to reduce greenhouse gas and fine particulate matter emissions than consumers in class 2 . On the other hand, because respondents in class 2 place a high value on the risk attribute, they were willing to pay a high cost of $286.47 \mathrm{KRW} / \mathrm{kWh}$ to reduce the risk of electric-power production. Assuming that the monthly average electricity usage per household in Korea is $380 \mathrm{kWh}$, this is a large amount, equivalent to KRW 108,859 (USD 91). In 2015, the number of households that used electricity was 14,419,000, and they consumed 65,619 GWh. Hence, an average of $380 \mathrm{kWh}$ was consumed monthly per household. The average monthly electricity charge per household in Korea was KRW 47,000 (USD 39) [39].

To link the preferences heterogeneity among classes to actual consumer segmentation, it is necessary to identify the cause of the heterogeneity of these preferences. To do this, this study examines characteristics of respondents in class 1 and class 2. Demographic variables such as gender, age, and household income are used to describe the characteristics of respondents in these classes. As shown in Table 5, the probability of respondents belonging to class 1 is higher when respondents have higher age and lower household income. There is no significant difference in the gender of respondents in the two classes.

Table 5. Estimation results of individual characteristics variables.

\begin{tabular}{cccc}
\hline & Variable & Estimates & Standard Deviation \\
\hline & Gender & 0.1852 & 0.2151 \\
Characteristics of class 1 & Age & $0.0233^{* * *}$ & 0.0079 \\
compared to class 2 & Household income & $-0.0998^{* *}$ & 0.0476 \\
& Constant & -0.6855 & 0.4291 \\
\hline
\end{tabular}

*** Statistically significant at $1 \%$ level, ${ }^{* *}$ Statistically significant at $5 \%$ level.

Several implications can be drawn via connections between the estimation results of individual characteristics (Table 5) and those of LCM (Tables 3 and 4). For instance, the relatively low household income for class 1 is a factor that leads respondents in class 1 to consider the electricity charge as more important $(29.3 \%)$. On the other hand, the tendency of respondents in class 1 with relatively high age and low household income to prefer environmentally friendly power sources differs from the results of existing studies. For example, Chen et al. [40] found that female respondents with higher income, higher level of education, and lower age generally have more pro-environmental attitudes and behavior. However, it seems that this proposition does not hold for Korea and/or power source, because respondents with lower income and higher age have a more pro-environmental preference structure for power sources, according to the analysis results of this study. On the other hand, respondents in class 2 with relatively low age and high household income tend to avoid the risk attribute of the power source. This proves that people with greater opportunity cost (i.e., more wealth and time to live their lives) are more sensitive to the risk attribute. Thus, people with lower age and higher household income tend to have higher preferences for risk and safety than for the environment.

The results of the LCM analysis prove the existence of heterogeneity in social preferences for power sources. Such preference heterogeneity makes it possible to interpret phenomena that were difficult to explain. For example, although the average public acceptance for nuclear energy in Korea is relatively high [41], it is unclear why such a strong opposition to the expansion of nuclear power has occurred. The existence of preference heterogeneity suggests that, while the average resident would support a specific energy policy, an important proportion of residents could oppose it [24]. Therefore, it is necessary to mediate the heterogeneity of preference to achieve a social consensus on future electricity mix. 


\subsection{Development of the Electricity Mix from a Demand-Side Perspective}

This section develops the electricity mix from a demand-side perspective based on the estimation results of LCM in Section 4.1. The choice probability of power source for each individual respondent is derived by applying the parameter estimates of 615 individual respondents and the level of attributes per established power source. This choice probability of individual respondent is calculated by using Equation (3) or (5). That is, the expected utility of an individual respondent $i$ for specific power source $j$ is obtained by summing the values, $\beta_{i}$ multiplied by $X_{j}$. Then, the choice probability of individual respondent for a specific power source is obtained by dividing the expected utility by the summed value of all the expected utility for five power sources. Using these choice probabilities of individual respondents, the average choice probability for total respondents $(N=615)$, class $1(N=313)$, and class $2(N=302)$ are calculated. The choice probabilities for various power sources with different attribute levels are considered as the electricity mix that reflects social preferences.

This study accounts for the choice probabilities of five power sources-coal-fired, oil, liquefied natural gas (LNG), nuclear power, and renewables-that constitute most of the power generation capacity in Korea [11]. In addition, this study establishes four scenarios to account for the electricity production cost and technological progress, and it calculates the choice probabilities of three groups of respondents (total respondents, class 1, and class 2) within LCM for each scenario.

First, the study refers to [42] for the level of greenhouse gas reduction rate. Compared to coal-fired power generation, nuclear and renewable power generation emit almost no greenhouse gas, and LNG reduces it by about half. Renewable power includes solar photovoltaic, wind, hydro, and ocean. There is no significant difference in oil. This study refers to [43,44] for the level of fine particulate matter reduction rate. While the fine particulate matter emissions from nuclear and renewable power generation are low, there is a possibility that the fine particulate matter emissions from coal power generation can double the level of emissions from current power sources. In the case of risk attribute, the study assumes that only nuclear power generation has this risk because it limits the risk to the danger from nuclear explosion and radiation exposure. In the case of outage time, the study assumes that the supply stability of renewable power generation is lower than that of other power sources $[29,45]$. In the case of dependence on the import of power source, Korea provides the primary energy supply by relying $100 \%$ on oil and nuclear energy imports, $98.41 \%$ on coal imports, and $99.12 \%$ on LNG imports [1].

In the case of each power source's LCOE, since there are fluctuations depending on situations and time, this study considers four scenarios. Scenario 1, which is the baseline scenario, is based on each energy source's LCOE in Korea. The price of Korean case in [46] was used for the level of LCOE.

Scenario 2 reflects the global average of LCOE rather than that of Korea, and the study refers to [47]. Accordingly, while the level of LCOE for renewables and LNG is significantly lower than that of Scenario 1, the level of LCOE for nuclear energy is set at a considerably high level. In the case of renewables, the level of LCOE is low due to favorable solar radiation and wind conditions in foreign countries compared to those in Korea and the economies of scale caused by large-scale facility construction. The unit price of LNG in Korea is relatively high because of the East Asian premium and additional cost in liquefaction. On the other hand, the level of LCOE for nuclear energy in Korea is lower than that in other countries because of the low cost of civil engineering work and neglected external costs. The levels of LCOE for coal and oil in Korea are similar to the global average values.

Scenario 3 assumes that technological development solves the problem of intermittency of renewable power generation. This scenario assumes that, while the level of LCOE for renewables increases, the stability improves because a battery energy storage system (BESS) for which capacity is equivalent to $10 \%$ of generation capacity is installed [48]. In this case, an additional price increase of 19.4 KRW/kWh is possible for the case of solar photovoltaic [48]. Hence, compared with the baseline scenario, the LCOE of renewables was increased by $19.4 \mathrm{KRW} / \mathrm{kWh}$, and the outage time was adjusted to zero. 
Finally, Scenario 4 accounts for the drop of renewables LCOE in addition to the situations set forth in Scenario 3. Therefore, Scenario 4 assumes that the price of renewables and outage time attribute are simultaneously improved due to future supply expansion and technological progress. To set attributes, this study uses the renewable price $125.79 \mathrm{KRW} / \mathrm{kWh}$ that accounts for the solar photovoltaic LCOE 106.39 KRW/kWh in 2024 [49] and an increased price of 19.4 KRW/kWh from a BESS installment. Table 6 summarizes the levels of attributes assigned to each scenario.

Table 6. Attributes levels for power sources in each scenario.

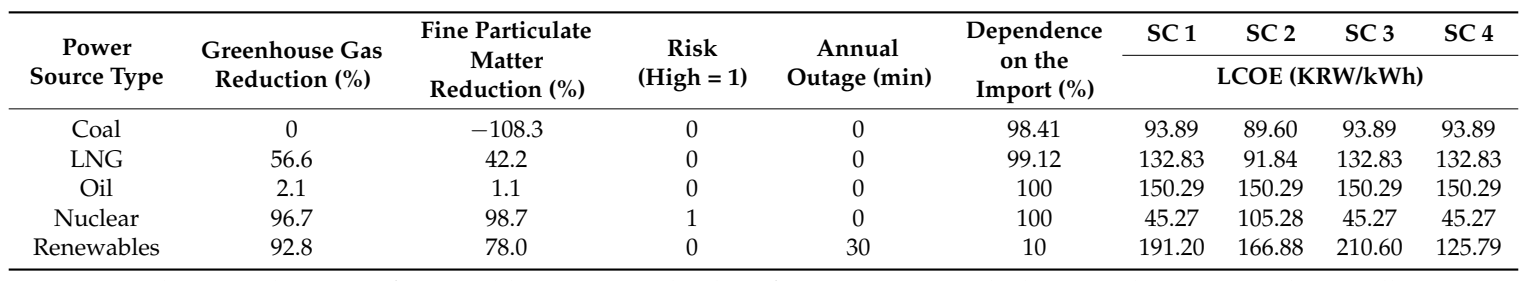

Note: The annual outage of renewables is assigned to be 0 for Scenarios 3 and 4 because they assume the installment of a battery energy storage system (BESS). LNG: liquefied natural gas. SC: Scenario.

The choice probabilities per scenario are shown in Table 7. These are the electricity mixes that reflect social preferences. In Scenario 1, respondents (in both class 1 and class 2) as a whole preferred power sources in the order of nuclear, coal-fired, renewable, LNG, and oil. While consumers preferred a relatively even portfolio for the remaining power sources, they preferred nuclear power the most. However, given the difference in choice probabilities between class 1 and class 2, the choice probabilities for respondents as a whole for individual power source do not, on average, apply to all citizens. In other words, while class 1 prefers nuclear and renewable power generation because of its sensitivity to environmental factors, its choice probability for coal-fired power generation that emits considerable greenhouse gasses and fine particulate matters is only $2.3 \%$. In contrast, class 2 has a high choice probability for traditional fossil fuels such as coal but very low choice probability for nuclear power $(8.7 \%)$. This reflects the characteristics of class 2 , which is sensitive to the risk attribute. Ultimately, the difference in preferences for coal and nuclear power-especially for nuclear power-between two classes is clearly confirmed through the difference in choice probabilities by class. Such preference heterogeneity for nuclear power means that social consensus on the proportion of nuclear power generation will not be easily achieved when establishing Korea's electricity mix in the future. Moreover, respondents in class 2 may not be cooperative in reducing the share of fossil fuels in Korea's energy supply because they have a high preference for coal-fired power generation.

Table 7. Electricity mix that reflects social preferences for each scenario.

\begin{tabular}{ccccccc}
\hline Scenario & Respondents & Coal & LNG & Oil & Nuclear & Renewables \\
\hline \multirow{2}{*}{ SC 1 } & Total & $19.8 \%$ & $17.6 \%$ & $11.2 \%$ & $32.9 \%$ & $18.5 \%$ \\
(Baseline) & Class 1 & $2.3 \%$ & $14.6 \%$ & $4.0 \%$ & $56.3 \%$ & $22.8 \%$ \\
& Class 2 & $38.0 \%$ & $20.7 \%$ & $18.7 \%$ & $8.7 \%$ & $13.9 \%$ \\
\hline \multirow{2}{*}{ SC 2 } & Total & $19.3 \%$ & $24.9 \%$ & $10.8 \%$ & $20.6 \%$ & $24.4 \%$ \\
& Class 1 & $2.5 \%$ & $24.6 \%$ & $4.4 \%$ & $35.3 \%$ & $33.1 \%$ \\
& Class 2 & $36.6 \%$ & $25.2 \%$ & $17.5 \%$ & $5.4 \%$ & $15.3 \%$ \\
\hline \multirow{2}{*}{ SC 3 } & Total & $18.7 \%$ & $16.4 \%$ & $10.5 \%$ & $30.3 \%$ & $24.1 \%$ \\
& Class 1 & $2.1 \%$ & $13.4 \%$ & $3.7 \%$ & $51.8 \%$ & $29.0 \%$ \\
& Class 2 & $35.9 \%$ & $19.5 \%$ & $17.6 \%$ & $8.1 \%$ & $19.1 \%$ \\
\hline \multirow{2}{*}{ SC 4 } & Total & $16.5 \%$ & $13.3 \%$ & $9.0 \%$ & $22.3 \%$ & $38.9 \%$ \\
& Class 1 & $1.5 \%$ & $9.7 \%$ & $2.7 \%$ & $37.3 \%$ & $48.9 \%$ \\
& Class 2 & $32.0 \%$ & $17.0 \%$ & $15.5 \%$ & $6.9 \%$ & $28.6 \%$ \\
\hline
\end{tabular}


Scenario 2 reflects the global LCOE level. Hence, it is shown that when Korea's LCOEs for each power source reach at the global level, the Korean society prefers power sources in the order of LNG, renewable, nuclear, coal-fired, and oil. This result illustrates the considerable increase in choice probabilities of LNG and renewables compared to Scenario 1 due to the relative price reduction of the two sources. In the case of LNG among the five power sources, preference heterogeneity is not large compared to other power sources in Scenarios 1 and 2 because they maintain choice probability at a certain level (mostly around 20\%) regardless of class. The choice probability increases for renewables and LNG but decreases for nuclear power in both classes compared to that in Scenario 1. It continues to be the case, however, that class 1 prefers nuclear power while avoiding coal and oil and class 2 prefers coal while avoiding nuclear power.

In Scenario 3, respondents as a whole prefer power sources in the order of nuclear, renewables, coal, LNG, and oil. For choice probabilities of each power source, there is not much difference from Scenario 1 except for the increase of choice probability for renewables $(18.5 \rightarrow 24.1 \%)$. Nevertheless, the result of Scenario 3 is meaningful because it confirms the relative effect of the price increase and supply stability improvement, which are two changes in the renewables that conflict in terms of consumer preference. In Scenario 3, the probability of choosing renewables is higher than in Scenario 1, and renewables are more preferred than coal. Thus, it is confirmed that the effect of supply stability improvement surpasses the effect of a price increase.

In Scenario 4, respondents as a whole prefer power sources in the order of renewables, nuclear, coal-fired, LNG, and oil. Scenario 4 is the only scenario where the entire group of respondents preferred renewables the most among the five sources. The probability of choosing renewables significantly increased to $38.9 \%$, indicating that improvement in supply stability and price competitiveness has a significant effect on enhancing social acceptance. The choice probability of renewables for class 1 is almost half $(48.9 \%)$, and that for class 2 is more than double $(28.6 \%)$ compared to that of Scenario 1 . Hence, if the detailed attributes of renewable sources become identical with those in Scenario 4, it will be possible to expand the renewable electricity supply in a more favorable social environment. Although the difference in perception of nuclear power remains the same between classes, the degree of difference decreases compared to that in Scenario 1 because the choice probability of nuclear power significantly decreases $(56.3 \rightarrow 37.3 \%)$ in class 1 .

By examining the difference in choice probabilities between two classes in each scenario, it is possible to examine whether the preferences heterogeneity for a certain power source is relatively larger or smaller (Table 8). The numbers in Table 8 are calculated as the difference between the choice probabilities of classes 1 and 2. The larger the difference in choice probabilities, the greater the difference in opinion towards certain power sources among classes. As shown in Table 8, respondents in classes 1 and 2 exhibit an extreme difference in their opinion towards nuclear and coal-fired power. As confirmed in the previous four scenarios, respondents in class 1 generally prefer nuclear while respondents in class 2 prefer coal-fired power. On the other hand, the difference in the choice probability of renewables is not large between classes compared to the two power sources. Renewable and nuclear energy are the main options for reducing future carbon emissions in the energy sector [50]. Hence, if Korea's power sector must expand renewables or nuclear power during the process of reducing fossil fuels, the expansion of the former power source is the one that has less social conflict. Therefore, the renewables should play a role in buffering the difference in opinion of the two classes. In addition, the Korean government should utilize LNG, which has the least heterogeneity of preferences between the two classes, as the bridge for transitioning to the future renewable energy era. The Asia-Pacific, where Korea is located, has vast natural gas resources [51]. This is another great advantage of LNG for Korea, which is highly dependent on energy imports. 
Table 8. Difference in the choice probabilities between class 1 and 2. *

\begin{tabular}{cccccc}
\hline Scenarios & Coal & LNG & Oil & Nuclear & Renewables \\
\hline SC 1 & $35.7 \% \mathrm{p}$ & $6.2 \% \mathrm{p}$ & $14.6 \% \mathrm{p}$ & $47.6 \% \mathrm{p}$ & $8.9 \% \mathrm{p}$ \\
SC 2 & $34.0 \% \mathrm{p}$ & $0.6 \% \mathrm{p}$ & $13.0 \% \mathrm{p}$ & $29.8 \% \mathrm{p}$ & $17.8 \% \mathrm{p}$ \\
SC 3 & $33.8 \% \mathrm{p}$ & $6.1 \% \mathrm{p}$ & $13.9 \% \mathrm{p}$ & $43.7 \% \mathrm{p}$ & $10.0 \% \mathrm{p}$ \\
SC 4 & $30.5 \% \mathrm{p}$ & $7.4 \% \mathrm{p}$ & $12.8 \% \mathrm{p}$ & $30.4 \% \mathrm{p}$ & $20.3 \% \mathrm{p}$ \\
Average & $33.5 \% \mathrm{p}$ & $5.1 \% \mathrm{p}$ & $13.6 \% \mathrm{p}$ & $37.9 \% \mathrm{p}$ & $14.3 \% \mathrm{p}$ \\
\hline
\end{tabular}

* Some rounding errors may exist.

By comparing Korea's planned electricity mix and the results of this study, it is possible to find implications for future electricity mix (Figure 1). In Korea, the proportion of power sources in the year 2015 is $39.9 \%$ for coal-fired, $22.5 \%$ for LNG, $1.9 \%$ for oil, $31.2 \%$ for nuclear energy, and $3.9 \%$ for renewables [52]. The comparison with the results of Scenarios 1 to 4 from this study confirm that it is necessary to change, especially, the proportion of coal-fired and renewable power generation. Increasing the proportion of renewable electricity to at least $18.5 \%$ and to a maximum of $38.9 \%$ while reducing the proportion of coal-fired generation to $20 \%$ or less will maximize the Korean consumer utility in the long run.

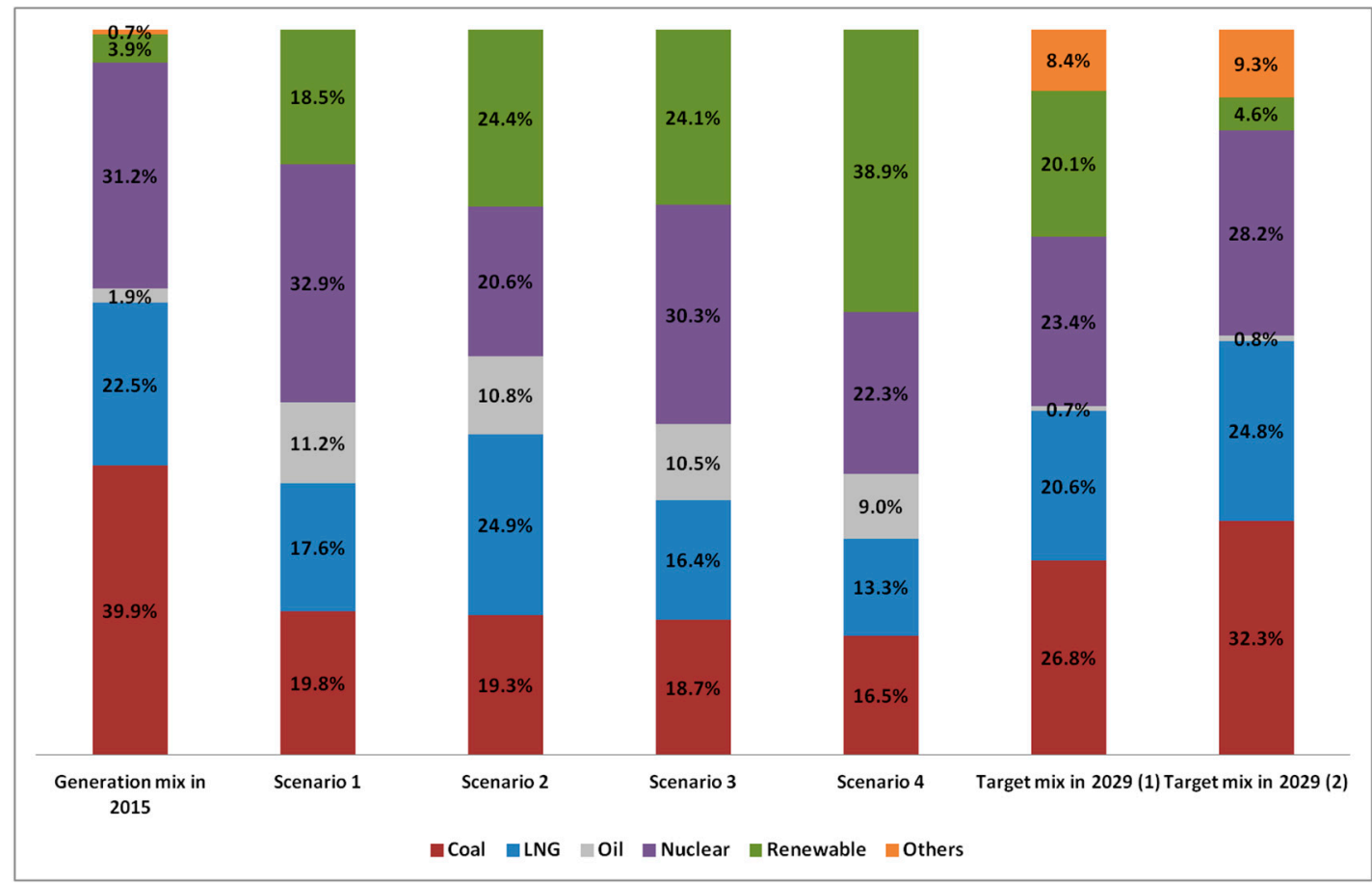

Figure 1. Comparison between Korea's electricity mix and results of study. Source: [52,53]. Note: Target mix in 2029 (1) is based on the generation capacity, target mix in 2029 (2) is based on peak load contribution, and the remaining are based on power generation amounts. Others include pumped-storage and cogeneration power generation.

It is also worth comparing the results of this study with existing studies that developed Korea's electricity mix from a supply-side perspective. With regard to Korea's optimal electricity mix based on the year 2030, Ahn et al. [14] proposed $19.20-24.58 \%$ for coal, $27.97-37.20 \%$ for LNG, $26.63-33.08 \%$ for nuclear energy, and $13.92-20.80 \%$ for renewables; in addition, Geem and Kim [18] proposed $21.1 \%$ for coal, $26.9 \%$ for LNG, $39.0 \%$ for nuclear energy, and $13.0 \%$ for renewables. The electricity mix in this study's Scenario 1, which did not assume technological progress for renewables, was $19.8 \%$ for coal, $17.6 \%$ for LNG, $11.2 \%$ for oil, $32.9 \%$ for nuclear energy, and $18.5 \%$ for renewables. Although it 
is difficult to make an exact comparison since the existing two studies do not include the oil source, there seems to be no major difference in the proportion of power sources between supply-side and demand-side perspectives except for that of LNG.

In the case of the study by Ahn et al. [14], it is confirmed that the electricity mix developed by cost-risk model considering $\mathrm{CO}_{2}$ and external costs within the electricity generation costs for each energy source, rather than the electricity mix developed by traditional least-cost model, is more similar to the electricity mix developed from demand-side perspective. This implies that when developing mid- and long-term electricity mix it is necessary to consider external costs of each power source as means for ensuring public support for it. On the other hand, in the case of the electricity mix proposed by Geem and Kim [18], the share of renewables was only 13.0\% even if it included Renewable Portfolio Standard (RPS) constraints. Our study predicted that Korean consumers are likely to want more than $18.5 \%$ of renewable share according to the scenarios. Therefore, in order for Korean government to achieve the share of renewable electricity that meets social preferences, more work needs to be done, such as elevating current RPS obligatory percentage, implementing additional renewable dissemination policies, and so on.

Lastly, electricity mixes developed by existing two studies and this study also provide important insights into the appropriate levels of nuclear power ratio, which is currently a very controversial issue in South Korea. All of the results of existing two studies and scenario 1 of this study indicate that about $30 \%$ of nuclear power ratio is appropriate with the current situation. However, according to the scenario analysis of this study, in terms of demand-side perspective, there is still room for a decrease in nuclear power ratio depending on a drop in renewables LCOE. Therefore, it is important to develop advanced renewable technologies in order for the Korean government to ensure public support in the process of reducing the nuclear power ratio.

\section{Conclusions}

The development of an optimal electricity mix is the basis for long-term electricity planning. This study developed an electricity mix from a demand-side perspective and proposed a method to reflect the heterogeneity of social preferences during the process. The proposed method was applied to the development of Korea's future electricity mix. The results confirmed that Korean society is divided into two classes based on preferences for power sources, and class 1 is relatively sensitive to the environmental attribute of power sources while class 2 is relatively sensitive to the risk attribute. The probability that respondents belong to class 1 was higher for respondents with higher age and lower income, while gender did not affect this probability. Korea's future electricity mix that reflects social preferences has the range of $16.5-19.8 \%$ for coal-fired, $13.3-24.9 \%$ for LNG, $9.0-11.2 \%$ for oil, $22.3-32.9 \%$ for nuclear, and $18.5-38.9 \%$ for renewables, according to the scenarios examined. The study confirmed that renewable sources represent fewer social conflicts than nuclear, in the process of reducing the ratio of fossil fuels in power sector. It also confirmed that it is necessary to utilize the LNG as a bridge to expand renewable energy. Furthermore, considerably increasing the proportion of renewable electricity, which is currently only $3.9 \%$, while decreasing the proportion of coal-fired $(39.9 \%)$ to half the current level will produce an electricity mix that meets social preferences in the long run.

Some research limitations are as follows. First, this study estimated the national electricity mix by surveying the general public. However, since the usage of electricity is divided into industrial, household, and commercial purposes, it is necessary to estimate the preferred electricity mix for each purpose. Second, regarding CBC analysis, this study considered consumer preferences at a specific time point and assumed that the preferences of respondents are constant over time. Other implications could result from considering a dynamic preference rather than a static preference. Third, this study limited the number of attributes of power sources to six because respondents are likely to have difficulty dealing with more than six attributes in a full-profile conjoint analysis [54]. Additional considerations of possible power source attributes could lead to richer implications. Fourth, this study 
established different scenarios by only focusing on renewable technological progress. This is because the Korean government has established the expansion of renewable supply as an important policy objective. However, there are technologies that could improve the attribute level of power generation for other power sources. If various technological progresses are considered simultaneously, it will be possible to develop other electricity mixes. Lastly, this study examined only three demographic variables-gender, age, and household income-in order to explain the difference in the characteristics of respondents in each class. However, it will be better to include other factors such as economic status other than household income, regional residence, political orientation, etc. This would help to provide additional implications for understanding consumer segmentation and designing related energy policies.

Despite the above limitations, this study is significant because it approached the development of an electricity mix from a demand-side perspective. From an empirical perspective, this study analyzed social preferences for electric-power sources and proposed the corresponding implications for Korea's energy market, in which the development of a sustainable long-term electricity mix has been controversial for many years. The Korean government must recognize that the development of a demand-supply plan of electricity from a demand-side perspective is as important as from a supply-side perspective and that the social acceptance of the electricity mix is increasingly important. Ultimately, the establishment of an electricity mix is a matter of social consensus. The electricity mix that considers social preferences presented in this study will become a meaningful index in the process of developing Korea's future electricity mix and electricity policies.

Acknowledgments: This work was supported by the Korea Energy Economics Institute (KEEI) grant funded by the South Korean Prime Minister's Office.

Author Contributions: Sung-Yoon Huh designed the study, outlined the methodology, and developed and estimated the model. Chul-Yong Lee reviewed the related literature, set up scenarios for simulation, and interpreted the results. All authors provided substantial writing contributions and significant comments on numerous drafts.

Conflicts of Interest: The authors declare no conflict of interest.

Appendix A. Alternatives Used in the Discrete Choice Experiment

Table A1. Set A.

\begin{tabular}{lllll}
\hline \multicolumn{1}{c}{ Attributes } & \multicolumn{1}{c}{ Type A } & \multicolumn{1}{c}{ Type B } & \multicolumn{1}{c}{ Type C } & \multicolumn{1}{c}{ Type D } \\
\hline $\begin{array}{l}\text { 1. Greenhouse gas emissions } \\
\text { 2. Fine particulate matter } \\
\text { emissions }\end{array}$ & $50 \%$ reduction & $0 \%$ reduction & $50 \%$ reduction & $100 \%$ reduction \\
\hline 3. Electricity charges & $100 \%$ reduction & $100 \%$ reduction & $50 \%$ reduction & $100 \%$ reduction \\
\hline $\begin{array}{l}\text { 4. Risk } \\
\text { 5. Annual outage time }\end{array}$ & Low & $50 \%$ decrease & $50 \%$ decrease & $0 \%$ increase \\
\hline $\begin{array}{l}\text { 6. Dependence on the } \\
\text { import of energy source }\end{array}$ & $\begin{array}{l}100 \% \text { import of } \\
\text { energy source }\end{array}$ & $\begin{array}{l}100 \% \text { import of } \\
\text { energy source }\end{array}$ & $\begin{array}{l}\text { High } \\
\text { energy source }\end{array}$ & $\begin{array}{l}\text { Low imporgy source } \\
\text { ener }\end{array}$ \\
\hline $\begin{array}{l}\text { Choose the one which you } \\
\text { most preferred }\end{array}$ & - & - & - & High \\
\hline
\end{tabular}


Table A2. Set B.

\begin{tabular}{|c|c|c|c|c|}
\hline Attributes & Type A & Type B & Type C & Type D \\
\hline 1. Greenhouse gas emissions & $100 \%$ reduction & $50 \%$ reduction & $0 \%$ reduction & $100 \%$ reduction \\
\hline $\begin{array}{l}\text { 2. Fine particulate matter } \\
\text { emissions }\end{array}$ & $0 \%$ reduction & $100 \%$ reduction & $100 \%$ reduction & $100 \%$ reduction \\
\hline 3. Electricity charges & $50 \%$ decrease & $0 \%$ increase & $50 \%$ decrease & $50 \%$ decrease \\
\hline 4. Risk & High & Low & Low & High \\
\hline 5. Annual outage time & About $0 \mathrm{~min} /$ year & About $0 \mathrm{~min} /$ year & About $0 \mathrm{~min} /$ year & About $30 \mathrm{~min} /$ year \\
\hline $\begin{array}{l}\text { 6. Dependence on the } \\
\text { import of energy source }\end{array}$ & $\begin{array}{l}100 \% \text { import of } \\
\text { energy source }\end{array}$ & $\begin{array}{l}0 \% \text { import of } \\
\text { energy source }\end{array}$ & $\begin{array}{l}100 \% \text { import of } \\
\text { energy source }\end{array}$ & $\begin{array}{l}0 \% \text { import of } \\
\text { energy source }\end{array}$ \\
\hline $\begin{array}{l}\text { Choose the one which you } \\
\text { most preferred }\end{array}$ & - & - & - & - \\
\hline
\end{tabular}

Table A3. Set C.

\begin{tabular}{|c|c|c|c|c|}
\hline Attributes & Type A & Type B & Type C & Type D \\
\hline 1. Greenhouse gas emissions & $100 \%$ reduction & $0 \%$ reduction & $50 \%$ reduction & $100 \%$ reduction \\
\hline $\begin{array}{l}\text { 2. Fine particulate matter } \\
\text { emissions }\end{array}$ & $0 \%$ reduction & $0 \%$ reduction & $0 \%$ reduction & $50 \%$ reduction \\
\hline 3. Electricity charges & $100 \%$ increase & $0 \%$ increase & $50 \%$ decrease & $0 \%$ increase \\
\hline 4. Risk & Low & Low & High & High \\
\hline 5. Annual outage time & About $30 \mathrm{~min} /$ year & About $30 \mathrm{~min} /$ year & About $0 \mathrm{~min} /$ year & About $0 \mathrm{~min} /$ year \\
\hline $\begin{array}{l}\text { 6. Dependence on the } \\
\text { import of energy source }\end{array}$ & $\begin{array}{l}100 \% \text { import of } \\
\text { energy source }\end{array}$ & $\begin{array}{l}0 \% \text { import of } \\
\text { energy source }\end{array}$ & $\begin{array}{l}0 \% \text { import of } \\
\text { energy source }\end{array}$ & $\begin{array}{l}100 \% \text { import of } \\
\text { energy source }\end{array}$ \\
\hline $\begin{array}{l}\text { Choose the one which you } \\
\text { most preferred }\end{array}$ & - & - & - & - \\
\hline
\end{tabular}

Table A4. Set D.

\begin{tabular}{|c|c|c|c|c|}
\hline Attributes & Type A & Type B & Type C & Type D \\
\hline 1. Greenhouse gas emissions & $100 \%$ reduction & $100 \%$ reduction & $0 \%$ reduction & $100 \%$ reduction \\
\hline $\begin{array}{l}\text { 2. Fine particulate matter } \\
\text { emissions }\end{array}$ & $100 \%$ reduction & $50 \%$ reduction & $50 \%$ reduction & $100 \%$ reduction \\
\hline 3. Electricity charges & $50 \%$ decrease & $50 \%$ decrease & $100 \%$ increase & $100 \%$ increase \\
\hline 4. Risk & High & Low & High & Low \\
\hline 5. Annual outage time & About $0 \mathrm{~min} /$ year & About $30 \mathrm{~min} /$ year & About $0 \mathrm{~min} /$ year & About $0 \mathrm{~min} /$ year \\
\hline $\begin{array}{l}\text { 6. Dependence on the } \\
\text { import of energy source }\end{array}$ & $\begin{array}{l}0 \% \text { import of } \\
\text { energy source- }\end{array}$ & $\begin{array}{l}100 \% \text { import of } \\
\text { energy source }\end{array}$ & $\begin{array}{l}0 \% \text { import of } \\
\text { energy source- }\end{array}$ & $\begin{array}{l}100 \% \text { import of } \\
\text { energy source }\end{array}$ \\
\hline $\begin{array}{l}\text { Choose the one which you } \\
\text { most preferred }\end{array}$ & - & - & - & - \\
\hline
\end{tabular}

\section{References}

1. Korea Energy Economics Institute. Yearbook of Energy Statistics; Korea Energy Economics Institute: Ulsan, Korea, 2016. (In Korean)

2. Awerbuch, S. Portfolio-based electricity generation planning: Policy implications for renewables and energy security. Mitig. Adapt. Strateg. Glob. Chang. 2006, 11, 693-710. [CrossRef]

3. Huang, Y.H.; Wu, J.H. A portfolio risk analysis on electricity supply planning. Energy Policy 2008, 36, 627-641. [CrossRef]

4. Biegler, T. The Hidden Costs of Electricity: Externalities of Power Generation in Australia; The Australian Academy of Technological Sciences and Engineering: Parkville, Australia, 2009. 
5. Weinzettel, J.; Havránek, M.; Scasny, M. A consumption-based indicator of the external costs of electricity. Ecol. Indic. 2012, 17, 68-76. [CrossRef]

6. Cabello, J.M.; Luque, M.; Miguel, F.; Ruiz, A.B.; Ruiz, F. A multiobjective interactive approach to determine the optimal electricity mix in Andalucía (Spain). Top 2014, 22, 109-127. [CrossRef]

7. Rentizelas, A.; Georgakellos, D. Incorporating life cycle external cost in optimization of the electricity generation mix. Energy Policy 2014, 65, 134-149. [CrossRef]

8. Purwanto, W.W.; Pratama, Y.W.; Nugroho, Y.S.; Warjito; Hertono, G.F.; Hartono, D.; Deendarlianto; Tezuka, T. Multi-objective optimization model for sustainable Indonesian electricity system: Analysis of economic, environment, and adequacy of energy sources. Renew. Energy 2015, 81, 308-318. [CrossRef]

9. Sithole, H.; Cockerill, T.T.; Hughes, K.J.; Ingham, D.B.; Ma, L.; Porter, R.T.J.; Pourkashanian, M. Developing an optimal electricity generation mix for the UK 2050 future. Energy 2016, 100, 363-373. [CrossRef]

10. Ryu, H.; Dorjragchaa, S.; Kim, Y.; Kim, K. Electricity-generation mix considering energy security and carbon emission mitigation: Case of Korea and Mongolia. Energy 2014, 64, 1071-1079. [CrossRef]

11. Augutis, J.; Martišauskas, L.; Krikštolaitis, R. Energy mix optimization from an energy security perspective. Energy Conv. Manag. 2015, 90, 300-314. [CrossRef]

12. Bhattacharya, A.; Kojima, S. Power sector investment risk and renewable energy: A Japanese case study using portfolio risk optimization method. Energy Policy 2012, 40, 69-80. [CrossRef]

13. Vazhayil, J.P.; Balasubramanian, R. Optimization of India's electricity generation portfolio using intelligent Pareto-search genetic algorithm. J. Electr. Power Energy Syst. 2014, 55, 13-20. [CrossRef]

14. Ahn, J.; Woo, J.; Lee, J. Optimal allocation of energy sources for sustainable development in South Korea: Focus on the electric power generation industry. Energy Policy 2015, 78, 78-90. [CrossRef]

15. Thangavelu, S.R.; Khambadkone, A.M.; Karimi, I.A. Long-term optimal energy mix planning towards high energy security and low GHG emission. Appl. Energy 2015, 154, 959-969. [CrossRef]

16. Tahir, A.C.; Bañares-Alcántara, R. A knowledge representation model for the optimisation of electricity generation mixes. Appl. Energy 2012, 97,77-83. [CrossRef]

17. Vidal-Amaro, J.J.; Østergaard, P.A.; Sheinbaum-Pardo, C. Optimal energy mix for transitioning from fossil fuels to renewable energy sources: The case of the Mexican electricity system. Appl. Energy 2015, 150, 80-96. [CrossRef]

18. Geem, Z.W.; Kim, J.H. Optimal energy mix with Renewable Portfolio Standards in Korea. Sustainability 2016, 8, 423. [CrossRef]

19. Bronfman, N.C.; Jimenez, R.B.; Arevalo, P.C.; Cifuentes, L.A. Understanding social acceptance of electricity generation sources. Energy Policy 2012, 46, 246-252. [CrossRef]

20. Heo, E. Global energy environment change and issues in Korea's future energy mix. Korean Energy Econ. Rev. 2011, 10, 187-205. (In Korean)

21. Contu, D.; Strazzera, E.; Mourato, S. Modeling individual preferences for energy sources: The case of IV generation nuclear energy in Italy. Ecol. Econ. 2016, 127, 37-58. [CrossRef]

22. Van Rijnsoever, F.J.; Van Mossel, A.; Broecks, K.P.F. Public acceptance of energy technologies: The effects of labeling, time, and heterogeneity in a discrete choice experiment. Renew. Sustain. Energy Rev. 2015, 45, 817-829. [CrossRef]

23. Willis, K.; Scarpa, R.; Gilroy, R.; Hamza, N. Renewable energy adoption in an ageing population: Heterogeneity in preferences for micro-generation technology adoption. Energy Policy 2011, 39, 6021-6029. [CrossRef]

24. Yoo, J.; Ready, R.C. Preference heterogeneity for renewable energy technology. Energy Econ. 2014, 42, 101-114. [CrossRef]

25. Foley, A.M.; Gallachóir, B.Ó.; Hur, J.; Baldick, R.; McKeogh, E.J. A strategic review of electricity systems models. Energy 2010, 35, 4522-4530. [CrossRef]

26. Byun, H.; Lee, C.Y. Analyzing Korean consumers' latent preferences for electricity generation sources with a hierarchical Bayesian logit model in a discrete choice experiment. Energy Policy 2017, 105, 294-302. [CrossRef]

27. Grösche, P.; Schröder, C. Eliciting public support for greening the electricity mix using random parameter techniques. Energy Econ. 2011, 33, 363-370. [CrossRef]

28. Kaenzig, J.; Heinzle, S.L.; Wustenhagen, R. Whatever the customer wants, the customer gets? Exploring the gap between consumer preferences and default electricity products in Germany. Energy Policy 2013, 53, 311-322. [CrossRef] 
29. Huh, S.Y.; Woo, J.; Lim, S.; Lee, Y.G.; Kim, C.S. What do customers want from improved residential electricity services? Evidence from a choice experiment. Energy Policy 2015, 85, 410-420. [CrossRef]

30. Welsch, H.; Biermann, P. Electricity supply preferences in Europe: Evidence from subjective well-being data. Resour. Energy Econ. 2014, 38, 38-60. [CrossRef]

31. Train, K.E. Discrete Choice Methods with Simulation, 3rd ed.; Cambridge University Press: New York, NY, USA, 2009.

32. Zhu, Q.; Zhang, Z. On using individual characteristics in the MNL latent class conjoint analysis: An empirical comparison of the nested approach versus the regression approach. Mark. Bull. 2009, 20, 1-12.

33. Greene, W.H.; Hensher, D.A. A latent class model for discrete choice analysis: Contrasts with mixed logit. Transp. Res. Part B Methodol. 2003, 37, 681-698. [CrossRef]

34. Magidson, J.; Vermunt, J.K. Latent class models for clustering: A comparison with K-means. Can. J. Mark. Res. 2002, 20, 37-44.

35. Goett, A.A.; Hudson, K.; Train, K.E. Customers' choice among retail energy suppliers: The willingness-to-pay for service attributes. Energy J. 2000, 21, 1-28. [CrossRef]

36. Borchers, A.M.; Duke, J.M.; Parsons, G.R. Does willingness to pay for green energy differ by source? Energy Policy 2007, 35, 3327-3334. [CrossRef]

37. Gracia, A.; Barreiro-Hurle, J.; Perez, L.P. Can renewable energy be financed with higher electricity prices? Evidence from a Spanish region. Energy Policy 2012, 50, 784-794. [CrossRef]

38. Van Putten, M.; Lijesen, M.; Ozel, T.; Vink, N.; Wevers, H. Valuing the preferences for micro-generation of renewables by househoulds. Energy 2014, 71, 596-604. [CrossRef]

39. Korea Electric Power Corporation. The Monthly Report on Major Electric Power Statistics; Korea Electric Power Corporation: Naju, Korea, 2016. (In Korean)

40. Chen, X.; Peterson, M.N.; Hull, V.; Lu, C.; Lee, G.D.; Hong, D.; Liu, J. Effects of attitudinal and sociodemographic factors on pro-environmental behavior in urban China. Environ. Conserv. 2011, 38, 45-52. [CrossRef]

41. Kim, Y.; Kim, W.; Kim, M. An international comparative analysis of public acceptance of nuclear energy. Energy Policy 2014, 66, 475-483. [CrossRef]

42. National Energy Technology Laboratory. Life Cycle Greenhouse Gas Emissions: Natural Gas and Power Production. 2015. Available online: https://www.eia.gov/conference/2015/pdf/presentations/skone.pdf (accessed on 27 July 2017).

43. Commission for Environment Cooperation. North American Power Plant Air Emissions. 2011. Available online: http:/ / www3.cec.org/islandora/en/item/10236-north-american-power-plant-air-emissions-en.pdf (accessed on 27 July 2017).

44. Ebright, R. Nuclear Power: An Environmental Friendly, Clean, Reliable and Safe Electrical Power Source for Today and for the Future. 2011. Available online: https:/ / energy.nd.edu/assets/37714/ebright_slides_02_ 21_20112.pdf (accessed on 27 July 2017).

45. Shin, J.; Woo, J.; Huh, S.Y.; Lee, J.; Jeong, G. Analyzing public preferences and increasing acceptability for the Renewable Portfolio Standard in Korea. Energy Econ. 2014, 42, 17-26. [CrossRef]

46. International Energy Agency. Projected Costs of Generating Electricity, 2015th ed.; OECD: Paris, France, 2015.

47. Bloomberg New Energy Finance. Levelized Cost of Electricity Update: H1 2016. 2016. Available online: https: / / about.bnef.com/ (accessed on 27 July 2017).

48. So, J. A Study on Economics of Solar and Wind Power Generation with Emphasis on Grid Stability; Korea Energy Economics Institute: Ulsan, Korea, 2014. (In Korean)

49. Lee, C.Y. Forecasting Price for the Renewable Energy Certificate in South Korea; Korea Energy Economics Institute: Ulsan, Korea, 2015. (In Korean)

50. Verbruggen, A. Renewable and nuclear power: A common future? Energy Policy 2008, 36, 4036-4047. [CrossRef]

51. Aguilera, R.F. The role of natural gas in a low carbon Asia Pacific. Appl. Energy 2014, 113, 1795-1800. [CrossRef]

52. Korea Power Exchange. Power Market Statistics in 2015; Korea Power Exchange: Naju, Korea, 2016. (In Korean) 
53. Korean Government Ministry of Trade Industry and Energy (MOTIE). The 7th Basic Plan of Long-Term Electricity Supply and Demand; MOTIE: Sejong, Korea, 2015. (In Korean)

54. Orme, B. Formulating Attributes and Levels in Conjoint Analysis; Sawtooth Software: Washington, DC, USA, 2002. 